\title{
Evaluation of Growth Functions on Japanese Quail Lines
}

\author{
Hamid Beiki ${ }^{1}$, Abbas Pakdel ${ }^{1}$, Mohammad Moradi-shahrbabak ${ }^{1}$ and Hossein Mehrban ${ }^{2}$ \\ ${ }^{1}$ Department of Animal Science, University college of Agriculture and Natural Resources, \\ University of Tehran, Karaj, 4111, Iran \\ ${ }^{2}$ University of shahrekord, shahrekord, 88155-137, Iran
}

\begin{abstract}
The aim of present study was to fit the best predictive equation to describe the growth curve of different Japanese quail lines. Moreover the effect of short-term divergent selection on the growth curve parameters was investigated. The quail lines utilized in the current study were two divergently selected lines for high (HW) and low (LW) 4-wk body weight (BW) and a control line (C). Determination and adjusted determination coefficients, relative error mean and standard deviation, mean square error, Akaike's information criteria and Schwarz Bayesian information criteria were used to evaluate the accuracy of prediction with the growth functions of Hyperbolastic (H1, H2, H3), Richards, Gompertz, Logistic and Von bertalanffy. Based on model behavior and statistical performance, the Gompertz and Logistic functions were not able to show a suitable fit for all three lines. The overall goodness of fit statistics in the HW line showed that the Richards function has the best fit to the data followed by H3, H2, H1, Von bertalanffy, Gompertz and Logistic functions, respectively. The overall results in the LW and C lines were similar to the HW line, except that Logistic function provided a better fit to the data than Gompertz. The study of growth pattern using Richards function revealed that short-term divergent selection altered the growth trajectory of selected lines through the changing of shape parameters and relative intensity of growth rates.
\end{abstract}

Key words: divergent selection, growth curve, Japanese quail

J. Poult. Sci., 50: 20-27, 2013

\section{Introduction}

Growth is a priority trait in poultry industry. Recently, researches are focused primarily on the Japanese quail, because of its low maintenance costs and short intergeneration interval. Moreover Japanese quail is considered to be a low-cost and useful function for poultry growth researches (Aggrey and Cheng, 1994; Jones, 1996; Decuypere et al., 2002).

A major step toward understanding growth process would be to explain the observed growth distribution. Traditionally, the mathematical functions called 'growth models' have been used to investigate the relationship between live weight and age (Fitzhugh, 1976; Anthony et al., 1996; Hyànková et al., 2001; Aggrey et al., 2003, 2009; Darmani-Kuhi et al., 2010). A useful growth function should describe data well and it must contain the biologically and physically meaningful parameters (France et al., 1996; Darmani-Kuhi et al., 2010). The growth functions have different specialties which must be noted prior to select them for description of

Received: November 13, 2011, Accepted: June 10, 2012

Released Online Advance Publication: July 25, 2012

Correspondence: Dr. H. Beiki, Department of Animal Science, University college of Agriculture and Natural Resources, University of Tehran, Karaj, P O Box 4111, Iran. (E-mail: Beiki@alumni.ut.ac.ir) observed growth data. The Logistic and Gompertz functions have fixed growth forms with the point of inflection at about 50 and $37 \%$ of the asymptote, respectively (Ricklefs, 1968). These parameter models are special cases of the more flexible Richards function, which a variable point of inflection has specified by the shape parameter $(\gamma)$ (Richards, 1959). The flexible functions are often generalized functions that encompass simpler functions for particular values of certain additional parameters (Darmani-Kuhi et al., 2010). Darmani-Kuhi et al. (2003) showed that description of growth in broilers by fixed-shape sigmoid functions such as Logistic or Gompertz curves may not be adequate because of the failure of the assumption that a constant curve shape holds across selected lines. Tabatabai et al. (2005) introduced the Hyperbolastic growth functions in 3 types including $\mathrm{H} 1$ (generalizes Logistic growth function); H2 (stand-alone); and H3 (generalizes Weibull growth function).

The results of other experiments showed that choosing the growth functions were species-specific, strain-specific and even line-specific (Ricklefs, 1979; Anthony et al., 1996). Hyánková et al. (2001) found that the shape of growth curve was not affected by short-term divergent selection in Japanese quail.

The aim of present study was to fit the best predictive function to describe the growth curve of divergently selected 
lines in Japanese quail. Moreover the effect of short-term divergent selection on the growth curve parameters was investigated.

\section{Material and Method}

\section{Experimental Birds}

The experimental population was originated from a commercial Japanese quail farming center in Yazd, Iran. Around 1,000 birds were transported to the animal research station of Tehran University. At first a number of birds were randomly selected from the base random bred population and distributed equally into 3 groups and allowed to reproduce. Then birds were divergently selected (phenotypic selection) for higher (HW) and lower (LW) 4-wk BW. No selection was carried out in the third group as the control line (C line).

In the selected lines, selection pressure in males was $10 \%$ and in females was $20 \%$. The cumulative response to selection over 7 generations for HW line was $19.88 \mathrm{~g}$ (males: $21.14 \mathrm{~g}$, females: $18.95 \mathrm{~g}$ ) and for the LW line was $-25.15 \mathrm{~g}$ (males: $-22.15 \mathrm{~g}$, females: $-28.15 \mathrm{~g}$ ).

For this experiment, 135 birds from the HW line, 239 birds from the LW line and 201 birds from the $\mathrm{C}$ line were weighted at hatch and placed into separate pens. All quails were supplied with balanced feed (i.e., standard commercial feed contain $28 \mathrm{~g} \mathrm{CP} / \mathrm{kg}$ and $2900 \mathrm{kcal} \mathrm{ME} / \mathrm{kg}$ ) and artificially lighted housing for 24 hours/day. Birds were kept in a room maintained at about $35^{\circ} \mathrm{C}$ during the first week, $28^{\circ} \mathrm{C}$ during the second week, and at $20 \sim 24^{\circ} \mathrm{C}$ from the $3 \mathrm{rd}$ week onwards. Food and water were available ad libitum. Until three weeks of age, the body weighs were measured daily on all chicks, and thereafter chicks were weighted at 24, 28, 32 and 42 days of age.

\section{Statistical Analysis}

The growth functions of Richards, Gompertz, Logistic, Von bertalanffy and Hyperbolastic growth functions including $\mathrm{H} 1, \mathrm{H} 2$ and $\mathrm{H} 3$, were fitted to the individual body weights in each line. The equation of growth functions used in this study and their time to inflection described in Table 1. All equations were fitted to the data by using SAS v.9.1.3 PROC NLIN (SAS Institute, 2005) procedure (Marquart algorithm).

The comparison of the models was carried out according to the model behavior when fitting the curves using nonlinear regression and statistical performance. A number of statistical analyses as follow were used to evaluate the general goodness-of-fit of each model.

Coefficient of determination $\left(R^{2}\right)=1-(S S E / S S T)$, where $S S E$; sum of square of errors, $S S T$; total sum of square.

Adjusted determination coefficient $\left(\right.$ Adj. $\left.R^{2}\right)=R^{2}-\mid(k-$ $1 / n-k)\left(1-R^{2}\right) \mid$, where $n$; the number of observations, $k$; the number of parameters.

Relative error $(R E)=\left|\left(y_{i}-\hat{y}_{i}\right)\left(y_{i}\right)^{-1}\right|$, where $y_{i}$ and $\hat{y}_{i}$; ob-

Table 1. Equation for seven growth curve functions and their time to inflection, used in this study

\begin{tabular}{|c|c|c|}
\hline \multirow[b]{2}{*}{ Function } & \multicolumn{2}{|r|}{ Equation } \\
\hline & Expression & Time to inflection \\
\hline H1 & $\begin{array}{l}w_{t}=\frac{M}{1+\alpha \exp [-M \beta t-\theta \arcsin h(t)]^{\prime}} \\
\alpha=\frac{M-w_{0}}{w_{0}} \exp \left[M \beta t_{0}+\theta \arcsin h\left(t_{0}\right)\right]\end{array}$ & {$\left[M-2 P\left(t^{*}\right)\right]\left(M \beta+\frac{\theta}{\sqrt{1+t^{* 2}}}\right)^{2}-\frac{\theta M t^{*}}{\left(1+t^{* 2}\right)^{3 / 2}}=0$} \\
\hline $\mathrm{H} 2$ & $\begin{aligned} w_{t} & =\frac{M}{1+\alpha \arcsin h\left[\exp \left(-M \beta t^{\gamma}\right)\right]^{\prime}} \\
\alpha & =\frac{M-w_{0}}{w_{0} \arcsin h\left[\exp \left(-M \beta t_{0}^{\gamma}\right)\right]}\end{aligned}$ & $\beta y t^{*}\left\{\operatorname{Mcsh}\left[\frac{2\left(M-P\left(t^{*}\right)\right)}{\alpha P\left(t^{*}\right)}\right]\right\}+(\gamma-1) \operatorname{coth}\left[\frac{M-P\left(t^{*}\right)}{\alpha P\left(t^{*}\right)}\right]=0$ \\
\hline $\mathrm{H} 3$ & $\begin{array}{l}w_{t}=M-\alpha \exp \left[-\beta t^{\gamma}-\arcsin h(\theta t)\right] \\
\alpha=\left(M-w_{0}\right) \exp \left[\beta t_{0}^{\gamma}+\arcsin h\left(\theta t_{0}\right)\right]\end{array}$ & {$\left[\beta \gamma t^{* \gamma-1}+\frac{\theta}{\sqrt{1+\theta^{2} t^{* 2}}}\right]^{2}-\left[\beta \gamma(\gamma-1) t^{* \gamma-2}-\frac{\theta^{2} t^{*}}{\left(1+\theta^{2} t^{* 2}\right)^{3 / 2}}\right]=0$} \\
\hline Logistic & $w_{t}=\frac{w_{0} M}{w_{0}\left(M-w_{0}\right) \exp (-\beta t)}$ & $t^{*}=\frac{1}{\beta} \ln \left(\frac{M-w_{0}}{w_{0}}\right)$ \\
\hline Richards & $w_{t}=M(1 \pm \vartheta \exp (-\beta t))^{-1 / r}$ & $t^{*}=-\frac{1}{\beta} \ln \left|\frac{\gamma}{\vartheta}\right|$ \\
\hline Gompertz & $w_{t}=w_{0} \exp \left[\left(\ln \frac{M}{w_{0}}\right)(1-\exp (-\beta t))\right]$ & $t^{*}=\frac{1}{\beta}\left[\ln \left(\frac{M}{w_{0}}\right)\right]$ \\
\hline $\begin{array}{l}\text { Von } \\
\text { bertalanffy }\end{array}$ & $w_{t}=\left[M^{\gamma}-\left(M^{\gamma}-w_{0}^{\gamma}\right) \exp (-\beta t)\right]^{1 / \gamma}$ & $t^{*}=\frac{1}{\beta} \ln \left[\frac{M^{\gamma}-w_{0}^{\gamma}}{\gamma M^{\gamma}}\right]$ \\
\hline
\end{tabular}

$\left(w_{t}\right)=$ live weight $(\mathrm{g})$ at age $t,(\beta)=$ relative intensity of growth rate, $(\vartheta),(\theta)$ and $(\gamma)=$ models parameters, $(M)=$ asymptotic body weight. In Hyperbolastic growth functions (H1 ((generalizes Logistic growth function), H2 (stand-alone) and H3 (generalizes Weibull growth function))), $(\alpha)=$ defined as a function of the other parameters $\left(M, \beta\right.$ and initial observed value $w_{0}$ at time $\left.t_{0}\right) . \quad\left(t^{*}\right)=$ time at inflection. (References) $=$ Hyperbolastic growth functions (Tabatabai et al., 2005), Richards (Hyànková et al., 2001), Von bertalanffy (Darmani-Kuhi et al., 2010), Gompertz (Sakomura et al., 2005), Logistic (Strathe et al., 2010). 
served and predicted body weights.

Relative error standard deviation $\left(S D_{R E}\right)=S D(R E)$, where $S D$; standard deviation.

Mean square error $(M S E)=S S E /(n-k)$, Where $n$; the number of observations, SSE; sum of square of errors, $k$; the number of parameters.

Akaike's information criteria $(A I C)=n \cdot \ln (S S E / n)+2 k$, where $n$; the number of observations, SSE; sum of square of errors, $k$; the number of parameters, (Akaike, 1974).

Schwarz Bayesian information criteria $(B I C)=n \cdot \ln (S S E / n)$ $+k \cdot \ln (n)$, where $n$; the number of observations, SSE; sum of square of errors, $k$; the number of parameters, (Schwarz, 1978).

Smaller Akaike or Bayesian information criteria or MSE (Aggrey et al., 2003) values for any model indicate the model fitted to the data better than other models (Dogan et al., 2010).

In the previous study of this authorship group (Beiki et al., 2011) no sexual dimorphism was observed in three investigated lines. Similar results have been reported by Oguz et al. (1996). Therefore the growth data in all three lines were analyzed without considering the sexual dimorphism. The obtained information's from the best function fitted to the data were analyzed by the following equation:

$$
y_{i j}=\mu+L_{i}+e_{i j}
$$

Where $y_{i j}=$ an observation of the jth bird from the ith line, $\mu=$ the population mean, $L_{i}=$ the effect of ith line and $e_{i j}$ the random error. Data were analyzed by SAS v.9.1.3 (SAS institute, 2005). In Hyperbolastic growth functions, time at inflection point was obtained using Microsoft Excel 2007 by numerical solution in Goal Seek procedure.

\section{Results}

The estimated parameters and goodness of fit criteria for all three lines are presented in Tables 2 and 3, respectively. The behavior of each function for HW line was illustrated in Fig. 1 as an example for all three lines. The results indicated that all growth functions were fitted to the data obtained from different lines without any difficulty by nonlinear regression.

Based on function behavior, the Gompertz and Logistic functions were not able to show a suitable fit to all three lines, while other growth functions provided an excellent fit (e.g., Fig. 1). Contrary to Ricklefs (1985), who stated that the fitted parameters using the Richards function are difficult to interpret biologically, the current study showed that fitting the Richards function can lead to meaningful biological indicators. The results for goodness of fit in different lines are as follow:

\section{The HW Line}

Determination and adjusted determination coefficients obtained from Richards, Von bertalanffy and $\mathrm{H} 3$ functions were the highest values. It must be noted that models with better fitting to the data will led to lower MSE values. When the functions ranked based on $M S E$, the Richards function showed the lowest MSE value and H3 function with MSE equal to 13.50 was superior than Von bertalanffy function with $M S E$ equal to 15.29 . In term of relative error means
$(\overline{R E})$, Richards function with $\overline{R E}$ equal to $0.035, \mathrm{H} 3$ with $\overline{R E}$ equal to 0.037 and Von bertalanffy with $\overline{R E}$ equal to 0.057 provided the best fit to the collected data set, respectively. The relative error standard deviation $\left(S D_{R E}\right)$ was lowest for Richards, $\mathrm{H} 3$ and $\mathrm{H} 2$ equations respectively.

Based on $A I C$ and $B I C$ values, the results indicated that data for HW line are better described by Richards function than any other equation. Fitting the growth functions to the data led to the lowest $A I C$ and $B I C$ values for $\mathrm{H} 3$ followed by $\mathrm{H} 2$ and Richards functions respectively.

The overall goodness of fit statistics in HW line indicated that the Richards function has the best fitting to the data followed by H3, H2, H1, Vonbertalanffy, Gompertz and Logistic functions, respectively.

\section{The LW Line}

The models comparison based on determination coefficients showed that Richards, H3and Von bertalanffy function led to better fit to the data than any other functions. The functions ranking based the goodness of fit by adjusted determination coefficients $\left(\right.$ Adj. $\left.R^{2}\right)$ were different from those of determination coefficients. The best functions from Adj. $R^{2}$ criteria point of view were Richards, Von bertalanffy and $\mathrm{H} 2$, respectively.

Fitting the growth functions led to the lowest $M S E, \overline{R E}$, $S D_{R E}, A I C$ and $B I C$ values for Richards, $\mathrm{H} 3$ and $\mathrm{H} 2$ functions respectively. In compare to the HW line, results for the LW line indicated that the Richards function described data better than any other functions.

All estimated statistic values in the LW line showed that Richards function provide the higher accuracy of fitness followed by H3, H2, H1, Von bertalanffy, Logistic and Gompertz functions, respectively.

\section{The C Line}

Based on determination coefficients, results indicated that Richards, $\mathrm{H} 3$ and $\mathrm{H} 2$ functions provide the best fit to the data, respectively. However when the best functions ranked based on adjusted determination coefficients, Richards, H2 and Von bertalanffy provided the best fit to data respectively. The lowest values for $M S E$ and $\overline{R E}$ obtained from Richards $\mathrm{H} 3$ and $\mathrm{H} 2$. Moreover, fitting the growth functions led to the lowest $S D_{R E}$, AIC and $B I C$ for Richards and $\mathrm{H} 2$ functions respectively.

The overall rank of the functions based on estimated statistic values in this line was the same as those reported in the LW line. In total, Richards function could be fitted best to the profile for all three lines. For this reason the Richards function parameters were used to assess the effect of divergent selection on the shape of growth curve. In Table 4 the Richards function parameters were presented for all three lines.

The $\beta$ parameter (Table 4 ) is expressed the maturation rate of the curve (i.e. the relative rate at which asymptotic body weight is reached) (Knízetová, 1995). In HW line, the low value of $\beta$ expressed lower maturation rate, compared to LW and $\mathrm{C}$ lines $(P<0.05)$. The age at maximum growth was occurred in the same age all three lines approximately (Table 2). Compared to the $\mathrm{C}$ line, the shape parameter value, $\gamma$, 

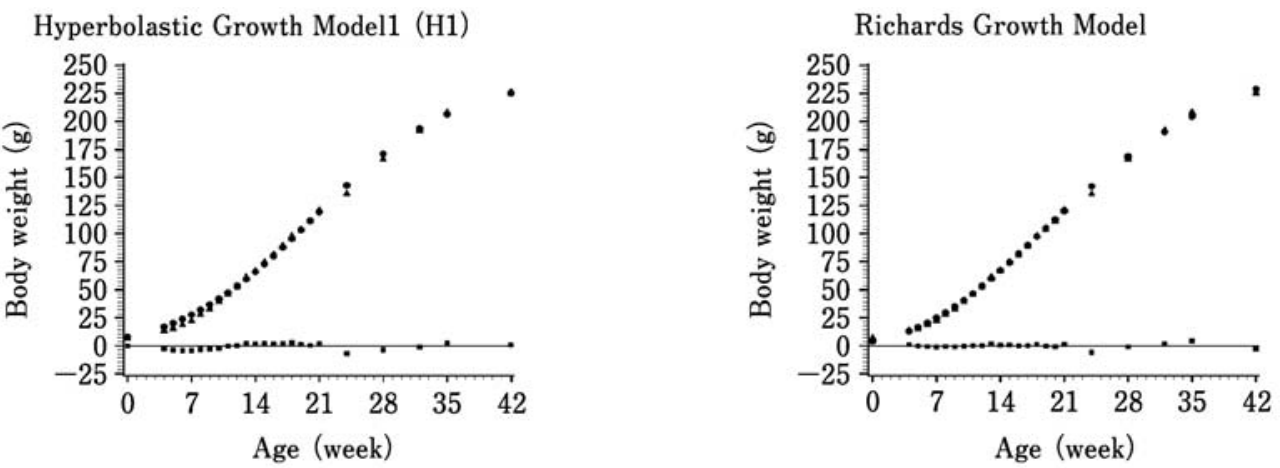

Hyperbolastic Growth Model2 (H2)
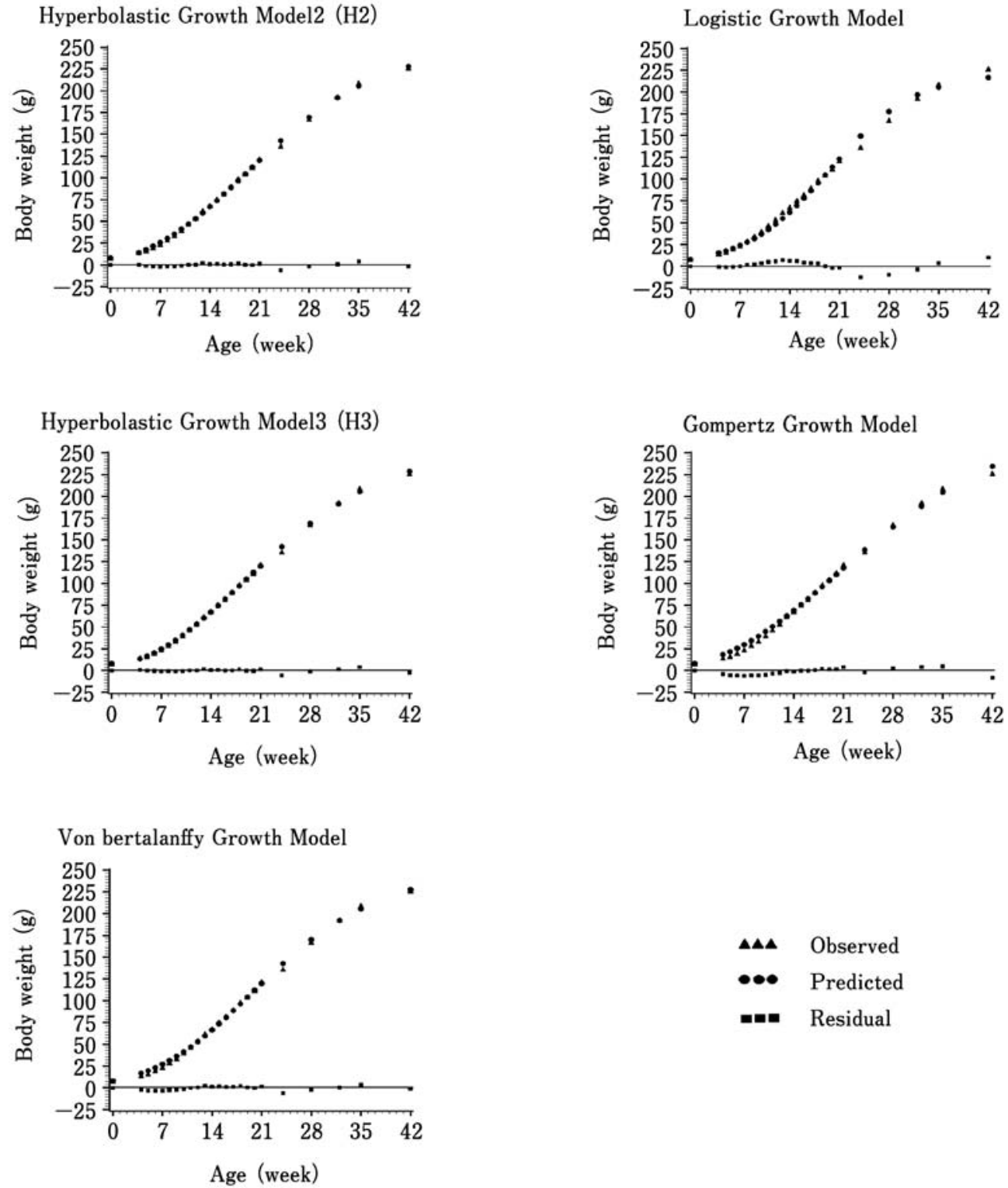

Fig. 1. Live weight and growth functions predicted BW vs. age (predicted values using 7 growth functions, namely include: $\mathrm{H1}, \mathrm{H2}$ and H3, Richards, Von bertalanffy, Logistic, Gompertz) from HW line. 
Table 2. Criteria that used to verifying of the fit of the predictive functions in divergent and control lines of Japanese quail

\begin{tabular}{crrrrrrrr}
\hline \hline & & \multicolumn{7}{c}{ Critaria } \\
\cline { 3 - 8 } Function & Line & \multicolumn{1}{c}{ MSE } & $R^{2}$ & Adj. $R^{2}$ & $\overline{R E}$ & SD $D_{R E}$ & AIC & BIC \\
\hline H1 & HW & 17.578 & 0.989 & 0.960 & 0.053 & 0.058 & 46.044 & 48.722 \\
H2 & HW & 14.995 & 0.991 & 0.964 & 0.043 & 0.044 & 43.585 & 46.305 \\
H3 & HW & 13.500 & 0.993 & 0.965 & 0.036 & 0.037 & 41.953 & 45.595 \\
Logistic & HW & 31.963 & 0.982 & 0.949 & 0.071 & 0.064 & 58.054 & 59.894 \\
Richards & HW & 12.339 & 0.995 & 0.978 & 0.035 & 0.038 & 43.926 & 47.763 \\
Gompertz & HW & 23.371 & 0.986 & 0.960 & 0.088 & 0.099 & 56.855 & 58.697 \\
Von bertalanffy & HW & 15.293 & 0.993 & 0.974 & 0.057 & 0.068 & 48.738 & 51.556 \\
H1 & LW & 13.116 & 0.987 & 0.949 & 0.047 & 0.049 & 36.856 & 39.534 \\
H2 & LW & 12.179 & 0.989 & 0.960 & 0.042 & 0.043 & 35.621 & 38.330 \\
H3 & LW & 11.722 & 0.991 & 0.958 & 0.036 & 0.036 & 34.669 & 38.319 \\
Logistic & LW & 17.773 & 0.982 & 0.948 & 0.064 & 0.063 & 45.235 & 47.038 \\
Richards & LW & 9.705 & 0.994 & 0.971 & 0.033 & 0.035 & 32.650 & 36.386 \\
Gompertz & LW & 19.988 & 0.979 & 0.940 & 0.088 & 0.093 & 48.952 & 50.755 \\
Von bertalanffy & LW & 13.253 & 0.990 & 0.960 & 0.055 & 0.060 & 39.826 & 42.621 \\
H1 & C & 12.174 & 0.993 & 0.974 & 0.045 & 0.061 & 39.621 & 42.336 \\
H2 & C & 10.916 & 0.994 & 0.977 & 0.043 & 0.058 & 39.119 & 41.896 \\
H3 & C & 9.784 & 0.994 & 0.973 & 0.037 & 0.051 & 35.813 & 39.411 \\
Logistic & C & 21.894 & 0.989 & 0.968 & 0.057 & 0.061 & 48.947 & 50.749 \\
Richards & C & 9.514 & 0.995 & 0.979 & 0.037 & 0.051 & 36.767 & 40.523 \\
Gompertz & C & 18.987 & 0.989 & 0.967 & 0.073 & 0.091 & 50.345 & 52.147 \\
Von bertalanffy & C & 11.502 & 0.994 & 0.977 & 0.046 & 0.063 & 40.649 & 43.441 \\
\hline
\end{tabular}

$(\mathrm{HW})=$ selected for increased 4-wk BW, $(\mathrm{LW})=$ selected for decreased $4-\mathrm{wk} \mathrm{BW},(\mathrm{C})=$ unselected random bred. $(M S E)$ $=$ mean square error, $\left(R^{2}\right)$ and $\left(A d j \cdot R^{2}\right)=$ determination and adjusted determination coefficient, respectively, $(\overline{R E})=$ mean relative error, $\left(S D_{R E}\right)=$ relative error standard deviation, $(A I C)=$ Akaike's information criteria, $(B I C)=$ Schwarz Bayesian information criteria.

Table 3. Growth curve parameters and time to inflection point for divergent and a control lines of Japanese quail using different growth functions

\begin{tabular}{|c|c|c|c|c|c|c|c|}
\hline \multirow[b]{2}{*}{ Function } & \multirow[b]{2}{*}{ Line } & \multicolumn{6}{|c|}{ Mean $\pm \mathrm{SE}$} \\
\hline & & $M$ & $\beta$ & $\theta$ & $\gamma$ & $\vartheta$ & $t^{*}$ \\
\hline $\mathrm{H} 1$ & HW & $209.44 \pm 4.49$ & $0.00078 \pm 0.00003$ & $0.25 \pm 0.02$ & - & - & $18.12 \pm 0.27$ \\
\hline $\mathrm{H} 2$ & HW & $247.10 \pm 5.63$ & $0.00332 \pm 0.00008$ & - & $0.58 \pm 0.01$ & - & $15.08 \pm 0.19$ \\
\hline H3 & HW & $242.81 \pm 9.07$ & $0.00674 \pm 0.00070$ & $2.06 \pm 0.07$ & $-0.005 \pm .001$ & - & $16.01 \pm 0.13$ \\
\hline Logistic & HW & $197.37 \pm 3.18$ & $0.17942 \pm 0.00169$ & - & - & - & $17.77 \pm 0.23$ \\
\hline Richards & HW & $305.11 \pm 10.17$ & $0.06440 \pm 0.00320$ & - & $-0.22 \pm 0.02$ & $17.02 \pm 0.40$ & $17.02 \pm 0.40$ \\
\hline Gompertz & HW & $317.23 \pm 5.61$ & $0.06495 \pm 0.00089$ & - & - & - & $20.41 \pm 0.35$ \\
\hline Von bertalanffy & HW & $236.18 \pm 5.78$ & $0.12129 \pm 0.00486$ & - & $-0.48 \pm 0.03$ & - & $18.13 \pm 0.27$ \\
\hline $\mathrm{H} 1$ & LW & $166.31 \pm 2.63$ & $0.00098 \pm 0.00003$ & $0.14 \pm 0.01$ & - & - & $18.26 \pm 0.22$ \\
\hline $\mathrm{H} 2$ & LW & $191.06 \pm 4.17$ & $0.00329 \pm .000070$ & - & $0.66 \pm 0.01$ & - & $15.17 \pm 0.17$ \\
\hline H3 & LW & $154.95 \pm 5.70$ & $0.00048 \pm 0.00005$ & $2.79 \pm 0.07$ & $0.01 \pm 0.0008$ & - & $16.25 \pm 0.17$ \\
\hline Logistic & LW & $157.83 \pm 1.96$ & $0.16430 \pm 0.00128$ & - & - & - & $17.95 \pm 0.17$ \\
\hline Richards & LW & $215.27 \pm 5.02$ & $0.08706 \pm 0.00200$ & - & $0.08 \pm 0.02$ & $0.99 \pm 0.17$ & $17.51 \pm 0.27$ \\
\hline Gompertz & LW & $271.46 \pm 5.51$ & $0.05838 \pm 0.00060$ & - & - & - & $21.95 \pm 0.33$ \\
\hline Von bertalanffy & LW & $178.17 \pm 3.71$ & $0.15105 \pm 0.00531$ & - & $-0.83 \pm 0.04$ & - & $18.29 \pm 0.23$ \\
\hline H1 & $\mathrm{C}$ & $192.64 \pm 2.54$ & $0.00080 \pm 0.00002$ & $0.25 \pm 0.01$ & - & - & $17.47 \pm 0.19$ \\
\hline $\mathrm{H} 2$ & $\mathrm{C}$ & $226.46 \pm 3.47$ & $0.00367 \pm 0.00006$ & - & $0.57 \pm 0.007$ & - & $14.34 \pm 0.13$ \\
\hline $\mathrm{H} 3$ & $\mathrm{C}$ & $184.12 \pm 4.45$ & $0.00086 \pm 0.00008$ & $2.65 \pm 0.07$ & $0.01 \pm 0.0008$ & - & $15.95 \pm 0.14$ \\
\hline Logistic & $\mathrm{C}$ & $176.22 \pm 1.93$ & $0.18281 \pm 0.00133$ & - & - & - & $16.78 \pm 0.16$ \\
\hline Richards & $\mathrm{C}$ & $240.34 \pm 3.71$ & $0.08361 \pm 0.00200$ & - & $0.005 \pm 0.02$ & $0.26 \pm 0.09$ & $16.73 \pm 0.23$ \\
\hline Gompertz & $\mathrm{C}$ & $291.63 \pm 5.07$ & $0.06572 \pm 0.00068$ & - & - & - & $19.74 \pm 0.26$ \\
\hline Von bertalanffy & $\mathrm{C}$ & $204.15 \pm 3.55$ & $0.13657 \pm 0.00380$ & - & $-0.60 \pm 0.03$ & - & $17.23 \pm 0.19$ \\
\hline
\end{tabular}


Table 4. Estimates of Richards growth curve parameters in three experimental Japanese quail lines

\begin{tabular}{crrr}
\hline \hline & \multicolumn{3}{c}{ Mean \pm SE } \\
\cline { 2 - 4 } Growth parameters & \multicolumn{1}{c}{ HW } & \multicolumn{1}{c}{$\mathrm{C}$} & \multicolumn{1}{c}{ HW } \\
\hline Asymptotic weight, $M(\mathrm{~g})$ & $305.111 \pm 6.997^{\mathrm{a}}$ & $240.347 \pm 5.679^{\mathrm{b}}$ & $215.277 \pm 5.429^{\mathrm{c}}$ \\
Shape parameter, $\gamma$ & $-0.227 \pm 0.032^{\mathrm{a}}$ & $0.005 \pm 0.026^{\mathrm{b}}$ & $0.086 \pm 0.025^{\mathrm{c}}$ \\
Relative intensity of growth, $\beta$ & $0.064 \pm 0.003^{\mathrm{a}}$ & $0.087 \pm 0.002^{\mathrm{a}}$ & $0.087 \pm 0.002^{\mathrm{c}}$ \\
Age at maximum growth, $t$ (day) & $17.060 \pm 0.343^{\mathrm{a}}$ & $16.793 \pm 0.278^{\mathrm{a}}$ & $17.513 \pm 0.266^{\mathrm{a}}$ \\
\hline
\end{tabular}

$(\mathrm{HW})=$ selected for increased $4-\mathrm{wk} \mathrm{BW},(\mathrm{LW})=$ selected for decreased $4-\mathrm{wk} \mathrm{BW},(\mathrm{C})=$ unselected random bred. Growth parameters with no common superscript $(\mathrm{a}, \mathrm{b}$ and $\mathrm{c})$ are significantly different $(P \leq 0.05)$. $(\beta)$ $=(\ln \phi) d^{-1},(\phi)=w^{\gamma},(w)=$ body weight, $(\gamma)=$ shape parameter, $(d)=$ day. This ratio estimates the maturation rate of the curve (i.e. the relative rate at which $M$ is reached) (Knízetová, 1995).

increased in the LW line and decreased in the HW line $(P<$ $0.05)$. Thus it can be concluded that divergent selection for 4-wk BW altered the shape of growth curve. The HW and LW lines have significantly higher and lower asymptotic body weight compared to the $\mathrm{C}$ line, respectively $(P<0.05)$. These results suggested that changes in the asymptotic weights were the output of changes in the relative intensity of growth and shape parameter during divergent selection for 4wk BW.

\section{Discussion}

Many functions have been developed to deal with sigmoid growth (Zeide, 1993) and new ones are continuously being proposed. However no function could accurately describe every biological phenomenon that researchers encounter in their practice (Tabatabai et al., 2005).

The Logistic model is symmetric around the point of inflection. Wright (1926) and Winsor (1932) stated that the log equation could describe the growth functions of individual organisms which displayed an asymmetrical S-shape better than Logistic functions. The Richards function which is a log function is more flexible than other functions and it can fit asymmetric growth patterns (Zhu et al., 1988; Yin et al., 2003). However, Richards function has more parameters than the Logistic function. Its flexibility, due to its shape parameter, $\gamma$, (dimensionless), makes it a generalized alternative to other models (e.g. monomolecular, Gompertz, Logistic, Von bertalanffy) (Thornley and France, 2007). The Gompertz and Logistic functions, have fixed growth shapes with inflection points at 37 and $50 \%$ of the asymptote, respectively. The Gompertz function has the same number of parameters as the Logistic function and the same as Von bertalanffy function (with flexible inflection point) can fit asymmetric growth, but they are not very flexible (Yin et al., 2003).

The $\mathrm{H} 1$ function has one parameter more than the Logistic and Gompertz functions, but it is more flexible and can fit asymmetric growth patterns as well as increasing and decreasing growth pattern. The $\mathrm{H} 2$ function has the same number of parameters as $\mathrm{H} 1$ and can fit asymmetric curves, but it can't fit decreasing growth patterns, so it is less flexible. The $\mathrm{H} 3$ function has the same flexibility as $\mathrm{H} 1$ function at the expense of one more parameter, similar to the Richards equations. Some of the flexibility of the H1, H2 and $\mathrm{H} 3$ functions were illustrated by Tabatabai et al. (2005).

Generally, statistics criteria were used in the current research confirmed that flexible growth functions such as Richards and Hyperbolastic (H1, H2 and H3) as an alternative to simpler equations (with a fixed point of inflection), provided higher accuracy of fitness (smaller MSE, $\overline{R E}, S D_{R E}$, $A I C$ and $B I C$ ) for quail growth data. Similar results have been reported in the meat and egg chicken strains by DarmaniKuhi et al. (2003). These results were in disagreement with the previous theory that stated Gompertz equation was the best fit for galiforms (Tzeng and Becker, 1981; Ricklefs, 1985; Anthony et al., 1991; Akbas and Oguz, 1998; Dogan et al., 2010). Brisbin et al. (1986), Knízetová et al. (1991a, 1991b), Darmani-Kuhi et al. (2003), Balcioğlu et al. (2005), Sezer and Tarhan (2005) and Darmani-Kuhi et al. (2010) successfully fitted Richards function to the poultry growth data. Further, in unselected quail population, Dogan et al. (2010) were compared different growth functions and reported that Gompertz was the best function followed by Richards, and H3. Ahmadi and Mottaghitalab (2007), Golian and Ahmadi (2008) reported that more flexibility of H3 and Richards function may lead to more accurate prediction and better fit to the broiler growth data than $\mathrm{H} 1$, $\mathrm{H} 2$ and Gompertzgrowth functions. Although the results of current study indicated that Richards growth function provided the best descriptions for Japanese quail growth data, it must be noted that this equation can sometimes lead to optimization problems and the process can fail to converge, primarily due to difficulty in estimating initial weight $\left(w_{0}\right)$ values (Darmani-Kuhi et al., 2010). However, DarmaniKuhi et al. (2010) reported that if $w_{0}$ is known and does not need to be estimated, fixing $w_{0}$ might solve non-convergence problem with the Richards function (as in present study).

Use of Richards function to assess the effect of divergent selection on the shape of growth curve indicated that selection for higher 4-wk BW has resulted in a correlated increase in asymptotic body weight, and a correlated decrease in the shape parameter of Richards function. The reverse was true when the birds were selected for lower 4-wk BW which is in agreement with previous results reported by Barbato (1992), 
Anthony et al. (1996) and Aggrey et al. (2003).

In conclusion, the comparison of seven growth functions in terms of the goodness of fit criteria revealed that flexible growth functions (especially Richards function) were the most appropriate functions to describe the age-related changes of body weight in different Japanese quail lines. This result is especially important when the behavior of a particular data set is not defined previously (Darmani-Kuhi et al., 2003). Nevertheless, selection of the best function requires special attention to characterize the growth patterns of animals in different environmental condition (Dogan et al., 2010). Therefore it should be reasonable to compare different functions to fit before to select the more accurate one.

\section{Acknowledgment}

The authors are very grateful to the University of Tehran, University college of Agriculture and Natural Resources for its financial support for this research project.

\section{References}

Aggrey SE and Cheng KM. Animal function analysis of genetic (co) variances for growth traits in Japanese quail. Poultry Science, 73: 1822-1828. 1994.

Aggrey SE, Ankra-Badu GA and Marks HL. Effect of long-term divergent selection on growth characteristics in Japanese quail. Poultry Science, 82: 538-542. 2003.

Aggrey SE. Logistic nonlinear mixed effects function for estimating growth parameters. Poultry Science, 88: 276-280. 2009.

Ahmadi $\mathrm{H}$ and Mottaghitalab M. Hyperbolastic functions as a new powerful tool to describe broiler growth kinetics. Poultry Science, 86: 2461-2465. 2007.

Akaike H. A new look at the statistical model identification. IEEE Transactions on Automatic Control, 19: 716-723. 1974.

Akbas Y and Oguz I. Growth cure parameters of lines of Japanese quail (Coturnix coturnix japonica), unselected and selected for four-week body weight. Arch Geflügelk, 62: 104-109. 1998.

Anthony NB, Emmerson DA, Nestor KE and Bacon WL. Comparison of Growth curves of weight selected populations of turkey, quail and chickens. Poultry Science, 70: 13-19. 1991.

Anthony NB, Nestor KE and Marks HL. Short-term selection for four-week body weight in Japanese quail. Poultry Science, 71: 1985-1993. 1996.

Balcioğlu MS, Kızılkaya K, Yolcu Hİ and Kabarağ HI. Analysis of growth characteristics in short-term divergently selected Japanese quail. South African Journal of Animal Science, 35: 83-89. 2005.

Barbato GF. Divergent selection for exponential growth rate at fourteen or forty-two days of age. 1. Early responses. Poultry Science, 71: 1985-1993. 1992.

Beiki H, Pakdel A and Moradi-Shahbabak M. The effect of divergent selection on 4-wk BW on the shape of growth curve in Japanese quail. Iranian Journal of Animal Science Research, 3: 38-45. 2011. (in Farsi with English abstract).

Brisbin IL, White GC, Bush PB and Mayack LA. Sigmoid growth analysis of wood ducks: The effect of sex, dietary protein and cadmium on parameters of the Richards function. Growth, 50: 41-50. 1986.

Darmani-Kuhi H, Kebreab E, Lopez S and France J. An Evaluation of Different Growth Functions for Describing the Profile of Live Weight with Time (Age) in Meat and Egg Strains of
Chicken. Poultry Science, 82: 1536-1543. 2003.

Darmani-Kuhi H, Porter T, López S, Kebreab E, Strathe AB, Dumas A, Dijkstra J and France J. A review of mathematical functions for the analysis of growth in poultry. World's Poultry Science Journal, 66: 227-239. 2010.

Decuypere E, Bruggeman V, Barbato GF and Buyse J. Growth and reproduction problems associated with selection for increased broiler meat production. (Muir WM and Aggrey SE. eds.) pp. 13-28. CABI Publishing. Cambridge. 2002.

Dogan N, Emre K, Mehmet ZF and Tulin A. Comparison of nonlinear growth functions to describe the growth in Japanese quail. Journal of Animal and Veterinary Advances, 9: 19611966. 2010.

Fitzhugh HA. Analysis of Growth curves and strategies for altering their shape. Journal of Animal Science, 42: 1036-1051. 1976.

France J, Dijkstra J and Dohanoa M.S. Growth functions and their application in animal science. Annales de Zootechnie, 45: 165-174. 1996.

Golian $\mathrm{H}$ and Ahmadi, H. Non-linear Hyperblastic functions for describing growth curve in classical strain of broiler chicken. Research Journal of Biological Science, 3: 1300-1304. 2008.

Hyánková L, Knízetová H, Dědková L and Hort J. Divergent selection for shape of growth curve in Japanese quail. 1. Responses in growth parameters and food conversion. British Poultry Science, 42: 583-589. 2001.

Jones RB. Fear and adaptability in poultry: insights, implications and imperatives. World's Poultry Science Journal, 52: 131174. 1996.

Knízetová H, Hyane kJ, Knize B and Roubicek J. Analysis of Growth curves in fowl. I. Chickens. British Poultry Science, 32: 1027-1038. 1991a.

Knízetová H, Hyane kJ, Knize B and Prochazkova H. Analysis of Growth curves in fowl. II. Ducks. British Poultry Science, 32: 1039-1053. 1991b.

Knízetová H. Comparative study of growth curvesin poultry. Genetic Selection Evolution, 27: 365-375. 1995.

Oguz I, Altan O, Kirkpinar F and Setter P. Body weights, carcass characteristics, organ weights, abdominal fat, and lipid content of liver and carcass in two lines of Japanese quail (Coturnix coturnix japonica), unselected and selected for four-week body weight. British Poultry Science, 37: 579-588. 1996.

Richards FJ. A flexible growth function for empirical use. Journal of Experimental Botany, 10: 290-300. 1959.

Richklefs RE. Patterns of growth in birds. Ibis, 110: 419-451. 1968.

Richklefs RE. Pattern of growth in birds. V. A comparative study of development in the starling, common term, and Japanese quail. AUK, 96: 10-30. 1979.

Richklefs RE. Modification of growth and development of muscles in poultry. Poultry Science, 64: 1563-1576. 1985.

Sakomura NK, Longo FA, Oviedo-Rondon EO, Boa-Viagem C and Ferraudo A. Functioning energy utilization and growth parameter description for broiler chickens. Poultry Science, 84: 1363-1369. 2005.

SAS Institute. SAS user's guide: Version 9.1.3. SAS Institute Inc., Cary, NC, USA. 2005.

Sezer M and Tarhan S. Function parameters of Growth curves of three meat-type lines of Japanese quail. Czech Journal of Animal Science, 50: 22-30. 2005.

Schwarz G. Estimating the dimension of a function. Annals of Statistics, 6: 461-464. 1978.

Strathe AB, Danfær A, Chwalibog A, Sørensen H and Kebreab E. A 
multivariate nonlinear mixed-effect method for analyzing energy partition in growing pigs. Journal of Animal Science, 88: 2361-2372. 2010.

Tabatabai M, Williams DK and Bursac Z. Hyperbolastic growth Models: Theory and application. Theoretical Biology and Medical Models, 2: 14-27. 2005.

Thornley, JHM and France J. Mathematical Functions in Agriculture: Quantitative Methods for the Plant, Animal and Ecological Sciences. 2nd ed. CABI Publishing. Wallingford. 2007.

Tzeng RY and Becker WA. Growth patterns of body and abdominal fat weights in male broiler chickens. Poultry Science, 60: 1101-1106. 1981.

Winsor CP. The Gompertz curve as a growth curve. Proceedings of the National Academy of Sciences of the United States of America, 18: 1-8. 1932.

Wright S. The biology of population growth; the natural increase of mankind - reviews. Journal of the American Statistical Association, 21: 493-497. 1926.

Yin X, Goudriaan J, Latinga EA, Vos J and Spiertz JH. A flexible sigmoid function of determinate growth. Annual Botany, 91: 361-371. 2003.

Zhu Q, Cao X and Luo Y. Growth analysis on the process of grain filling in rice. Acta Agronomica Sinica, 14: 182-193. 1988.

Zeide B. Analysis of growth equations. Forest Science, 39: 594616. 1993. 